\title{
VISION METHODS OF EXAMINING THE CLEANLINESS OF TEXTILE MATERIALS
}

\begin{abstract}
SUMMARY
This article discusses methods of assessment for the cleanliness of materials made of cotton and polyester soiled with oil and pigment. Cleanliness tests were carried out using the vision method as well as nanometre-scale examination of fibre surface, and their results presented. This article describes a method of image analysis and the adopted indices associated with cleanliness visible on the image of the tested material. Also, nanometre-scale images of fibre surfaces were presented, with the differences between clean and filthy fibres pointed out.
\end{abstract}

Keywords: control, nano-scanning, soiled, fabric, dirty

\section{WIZYJNE METODY BADANIA CZYSTOŚCI MATERIALÓW WEÓKIENNICZYCH}

Artykut omawia metody oceny czystości materiatu wykonanego z bawetny i poliestru, zabrudzonego olejem i pigmentami. Przedstawiono wyniki badań czystości wykonane metoda wizyjna i metoda oceny powierzchni wtókien wykonana $w$ skali nanometra. $W$ artykule opisano metode analizy obrazu oraz przyjęte współczynniki powiqzane z czystościq widoczne na obrazie badanego materiatu. Przedstawiono również obrazy powierzchni wtókien wykonane w skali nanometra ze wskazaniem różnic pomiędzy włóknami czystymi i zabrudzonymi.

Slowa kluczowe: metoda wizyjna, kontrola produktu,nanoskanowanie, zabrudzenia materiałów

\section{INTRODUCTION}

Utilization of fabrics and clothing made from them is accompanied by complicated processes of deposition of soils on the fabrics, penetration of polluting substances inside the materials, and their fixation on the fibres. The main negative result of filthiness is the change of characteristics of the materials: loss of brightness and clearness of colouring, worsening of the hygienic attributes, foul smell, and decrease in durability. The process of stain removal is complicated by the diversity of polluting substances on textile fabrics that are distinguished by their chemical nature, polarity and insolubility in washing mediums (water or organic solvent) (Volkov 1985, Fedorova 2005). First of all, filthiness of materials depends on the chemical nature of fibres and the presence of filament channels, cracks and other surface roughness, where pollution particles are held. The smallest soil particles penetrate deep into the fibres, while bigger ones are held between the fibres, and the largest ones are situated between the warp and the weft of the threads. Filthiness also depends on the thread structure and texture (Paraska 2010). The stronger the twist, the greater the density and the harder it is for the dirt to penetrate into the fibre. The important fact is how long the pollution has been on the fabric, since the process of diffusion of dirt into the fibres takes place during prolonged contact between them. The presence of sticky films of oil or fatty pollution on material surfaces increases its polluting ability, fixing of soil, and causes their adhesion and formation of stable complexes of pollution, resulting in the filling of pores of the textile material. As a result of the adsorption of the pollutants on the fibre surface, dense layers of dirt are formed on the surface of materials. Thus, the hygienic properties deteriorate and the process of dirt removal from textiles becomes more complicated. Clothing becomes stiff and uncomfortable for further use. To clean textile materials effectively and choose the chemicals for intensification of the washing process, it is necessary to know the mechanism of interaction between fibres and soils, and the quantitative and qualitative characteristics of filthiness of materials (Karvan 2003). Consideration of the indices of dirt retention allows us to predict the course of the soil removal process, which, in turn, will promote high-quality cleaning of textile materials without worsening the performance properties of clothing.

\section{ANALYSIS OF FABRIC CLEANLINESS WITH A VISION SYSTEM}

However, in practice, the definition of textile contamination is connected with certain difficulties, especially the nature and structure of artificial polluting substances, methods of their application and fixation, and the method of determination of their amount (Paraska 2006). Thus, the purpose of this research is the development of an algorithm of vision characterization of the filthiness of materials (Kowal 2009, 2010).

\footnotetext{
* Department of Chemical Technology, Faculty of Technology and Design, Khmelnitsky National University, Khmelnitsky, Ukraine; olgaparaska@gmail.com

** AGH University of Science and Technology, Department of Process Control, Faculty of Mechanical Engineering and Robotics, Krakow, Poland; andrzej.sioma@agh.edu.pl

*** Department of Chemistry, Faculty of Technology and Design, Khmelnitsky National University, Khmelnitsky, Ukraine; karvan@ukr.net
} 
Application of advanced information technologies as well as nano-, bio-, plasma, laser and other technologies, using modern research methods (X-ray diffractions, scanning and transmission electron microscopy, infrared spectroscopy methods, X-ray analysis, etc.) allows to conduct comprehensive facilities research at all levels of structural organization (Paraska 2010).

The main objective of this research is to obtain images of clean and polluted materials and to develop techniques for vision assessment of the rate and extent of soiling of textile materials. The scanning of the material surface at nanometre scale was conducted during the research with the help of a nano-scanner and a digital microscope. In this case, we obtained 3D images of material surfaces (Sioma 2010, 2011).

Fabric cleanliness tests were conducted at the vision station and the nano-technologies station developed in the Department of Process Control at AGH University of Science and Technology, Krakow, Poland.

For test purposes, fabric made of cotton (100\% cotton) and polyester ( $100 \%$ polyester) were used. The soiling was associated with the presence of oil and pigments on the textile fibres. Samples of fabrics were treated with the model composition of pollutants, and then dried at a temperature of $20^{\circ} \mathrm{C}$.

This study used a vision system with a resolution of $2560 \times 1920$ pixels with a monochrome CMOS sensor. Images were taken in an 8-bit grey scale with illumination from LED lamps to enable the creation of images both in the light reflected from the tested material and in the light passing through the material. The vision system was equipped with two types of lenses. The first is a telecentric measuring lens that allows observation of a large portion of the material and assessment of the degree of soiling. The second type is a microscopic lens, which was used to enlarge the assessed portion of the material and verify the quality of the algorithm developed for the purpose of evaluating the degree of contamination. In the study of surface topography, a digital measuring microscope was also used, enabling the construction of a three-dimensional image of the surface enlarged from 300 to 1000 times.

Figure 1a shows an image of clean polyester taken with the telecentric lens, with illumination passing through the material. Figure $1 \mathrm{~b}$ shows an image of clean polyester taken with the microscopic lens, with light reflected from the material.

However, the technological process of production of textiles from cotton fibre and polyester fibre conducted in industrial conditions generates a need to assess the cleanliness of the material. During the process, dirt is deposited on the fibres in the form of particles of water, oil, pigment or other chemicals used in the process. Both during production and after its completion, the material should be examined from time to time in order to control the degree of soiling.

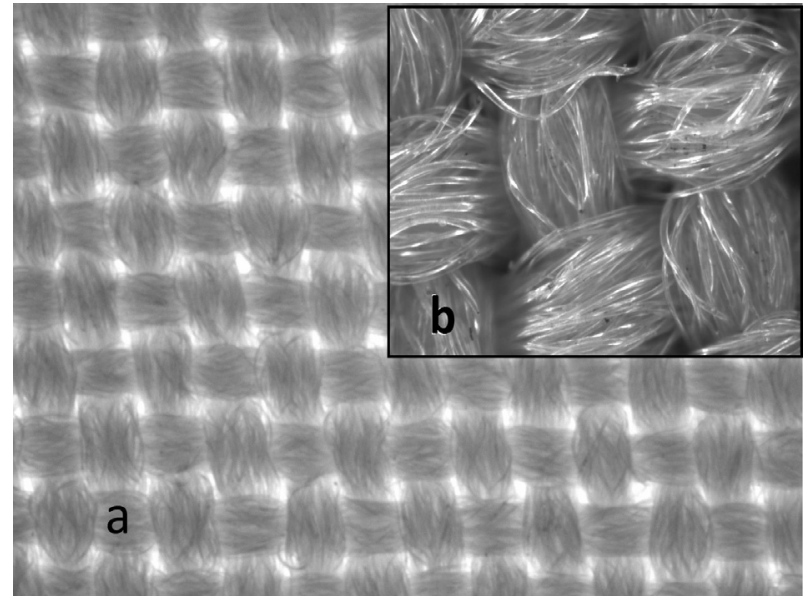

Fig. 1. Clean polyester (a) and enlarged portion of the material (b)

An image of clean cotton was prepared in an identical way. The image of cotton shows a typical arrangement of the fabric and fibre structure (Fig. 2).

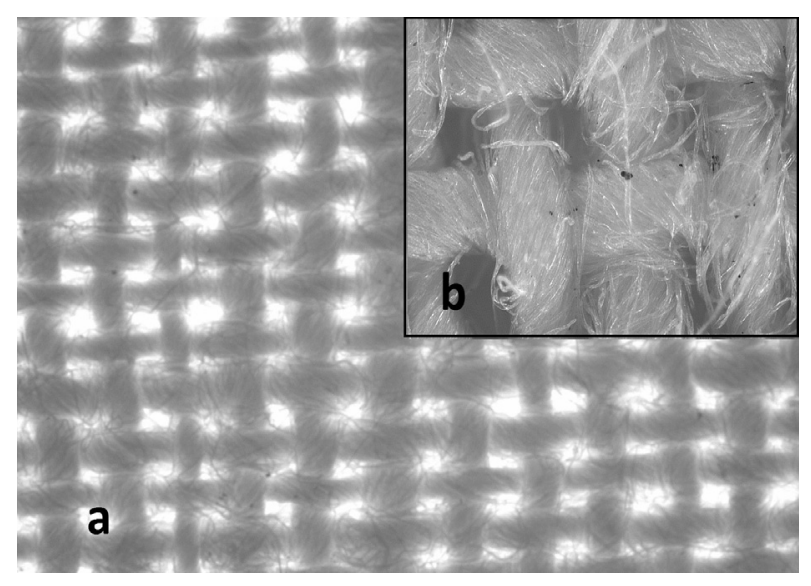

Fig. 2. Clean cotton (a) and enlarged portion of the material (b)

The figures below show images of polyester and cotton with visible dirt deposited during the manufacturing process. Images shown in Figures 3 and 4 were made in the light reflected from the material.

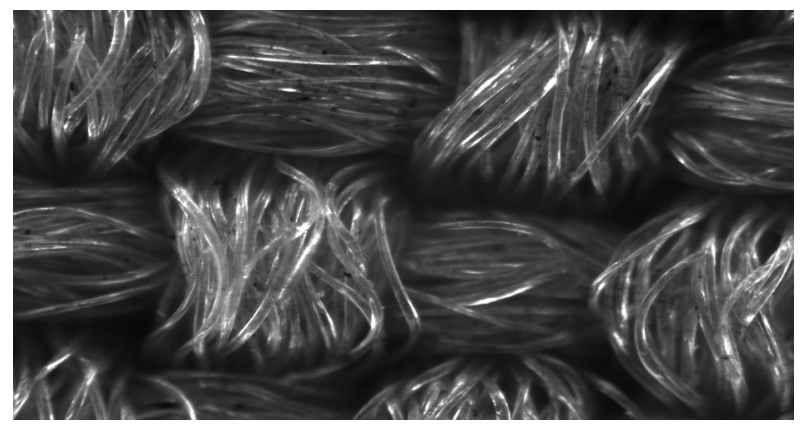

Fig. 3. Soiled portion of fabric made of polyester fibres 


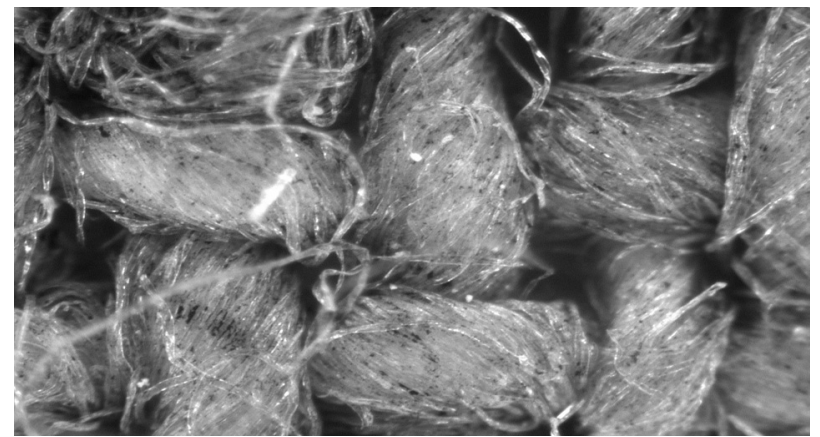

Fig. 4. Soiled portion of fabric made of cotton

Control of contamination of the material can be performed on samples selected from the technological process at the plant's laboratory. For that purpose, conventional optical microscopes as well as digital optical microscopes may be used to enable the construction of a three-dimensional image of the surface with a very large depth of field. Such a 3D image reveals any inclusions and dirt, not only on the surface layer of the material, but also between the fibres deep in the material. Figure 5 shows a three-dimensional image of clean cotton. The image shown in Figure 6 presents fabric made of cotton fibres soiled during the manufacturing process.

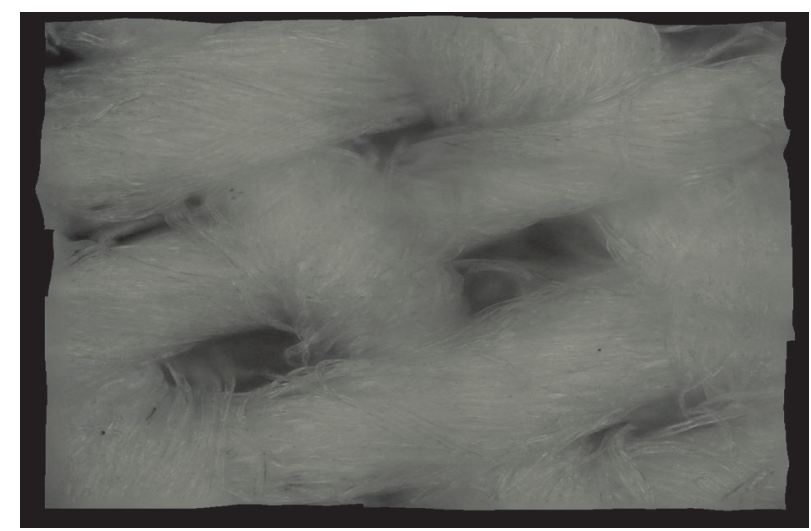

Fig. 5. Clean fabric made of cotton fibres

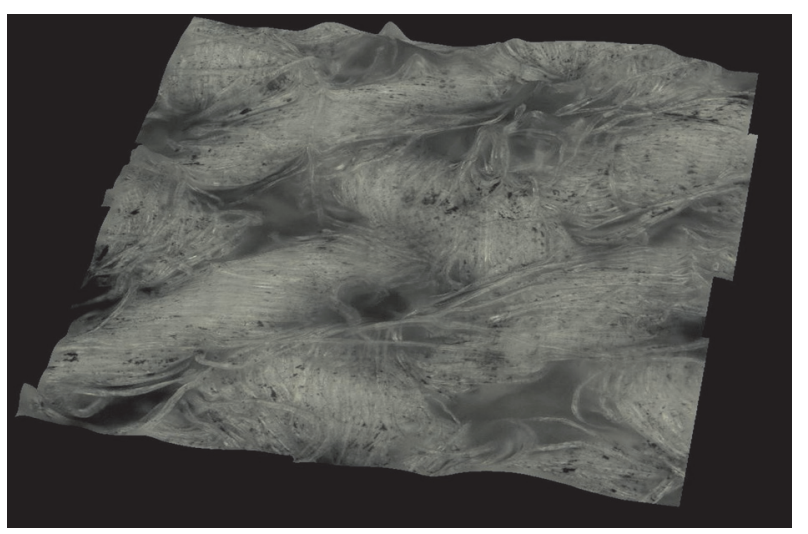

Fig. 6. Soiled fabric made of cotton fibres
Microscope inspection is an effective method often used in industry. However, it does not offer a rapid response to changes in the cleanliness of the material produced.

The aim of this project was to develop an automatic system for continuous monitoring of contamination of the material passing through the technological line between the successive technological operations. To accomplish this task, a vision system equipped with a monochrome CMOS sensor was chosen. The camera in the vision system can perform up to 50 inspections per second and enables incorporation of a measurement signal describing the degree of contamination of the material directly into the line control system. In the phase of testing the system and the algorithms developed for textile examination, the camera was simultaneously watching clean and filthy material. This enabled comparative evaluation of the tested material in relation to material previously determined to be clean. In the top part of Figure 7, there is soiled cotton (sample B), and in the bottom part - clean cotton (sample A).

For testing the cleanliness of the material, several parameters indirectly describing the cleanliness parameter were chosen. During testing, clean reference material, described as sample A, and soiled materials, described as samples from group B, were used. Figure 7 shows an image taken with transmitted light and shows the difference between clean and dirty material for sample A and B of the material. The light, i.e. its colour and intensity, is chosen on the basis of analysis of the properties and colour of the tested material.

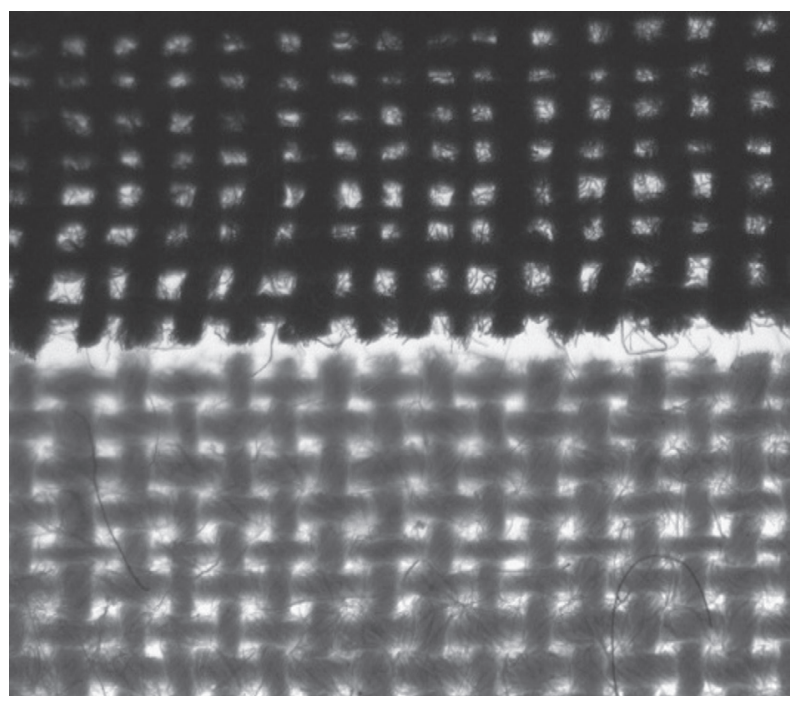

Fig. 7. Clean and soiled cotton

Sample A was used as a calibration standard for each of the discussed methods for imaging. In the image of that sample, characteristic features such as the intensity and shape of cotton fibres, the spacing between fibres, etc. were determined. Then, based on those patterns, the limit values were defined in a vision assessment programme, and testing of samples from group B was carried out. 
The first parameter used was the assessment of fibre micro-edges, which had been identified using contextual image transformations. In those transformations, the intensity of each pixel of the resulting image is determined based on the analysis of many pixels in the source image. Such an analysis requires the development of a function and definition of its value, in which the arguments are the intensity values of pixels forming the structural element in the source image. This study used a structural element in the form of a $3 \times 3$ sensor to determine the edges of both types of material, i.e. clean and soiled. The result of this comparative analysis is shown in Figure 8.
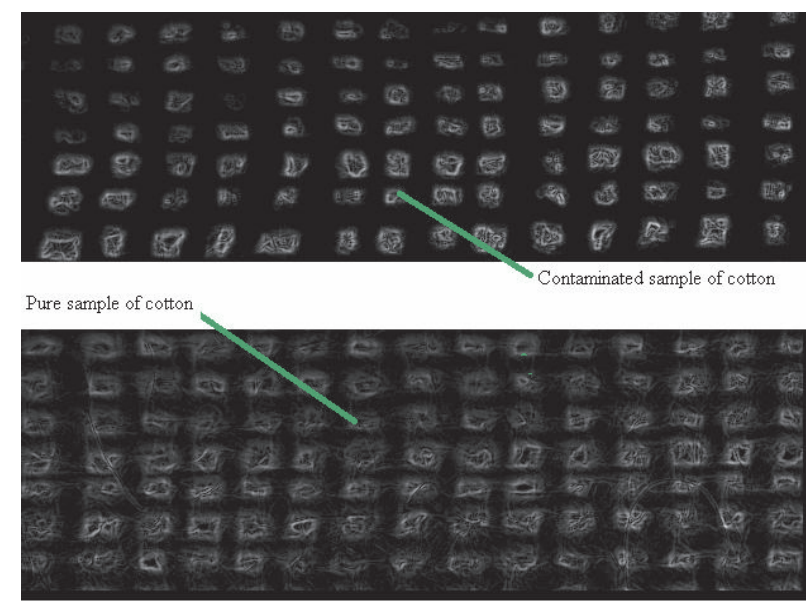

Fig. 8. Cotton fabrics after contextual transformation

With such an image of the material prepared, index $\mathrm{W}_{\mathrm{K}}$ was proposed to account for the shape, the surface area, and the number of designated micro-edges. The image presented above shows significant differences in the distribution, filling and the shape of the designated micro-edges. In the image of clean cotton, regular clusters of rectangular microedges with similar overall dimensions can be seen.

To assess the degree of contamination, one may also use an image of the materials subjected to binarization. The example discussed below uses single threshold binarization. The use of a single threshold allows for the transformation to present the difference between clean and soiled material in a very clear way. Figure 9 shows an image after binarization and graphically presents the difference between soiled and clean material.

In assessing the shape and size of the stains and the average intensity of the image after binarization, another assessment index was proposed, $\mathrm{W}_{\mathrm{B}}$, to describe the cleanliness of the material. Also, the contextual transformation was used in the evaluation algorithm as an auxiliary index to enable an analysis of the bright parts of the image of the material, i.e. the gaps between the cotton fibres. The transformation allows for the detection of the shape and edges of openings between the fibres and the strengthening of selected edges. That index was described as $\mathrm{W}_{\mathrm{G}}$ and presented in Figure 10.

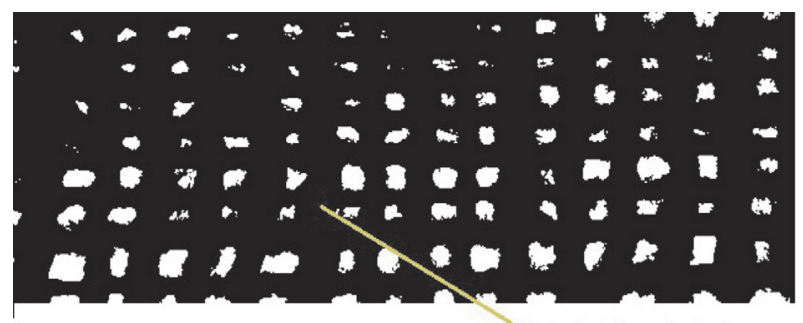

Contaminated sample of cotton

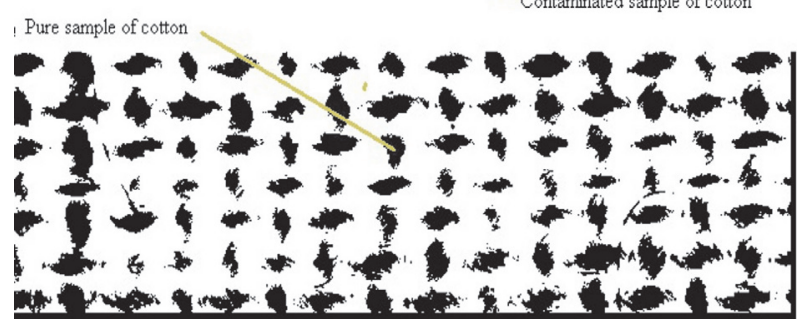

Fig. 9. Binarization of the image of materials
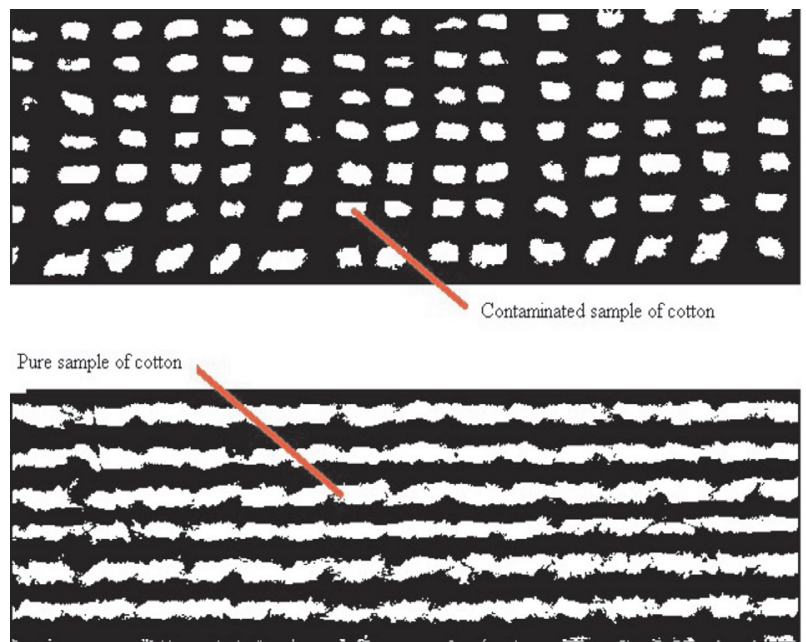

Fig. 10. Analysis of the shape of gaps between fibres

A final evaluation of the cleanliness of the material is performed by examining all the indices identified during image analysis. Indices $\mathrm{W}_{\mathrm{K}}, \mathrm{W}_{\mathrm{B}}, \mathrm{W}_{\mathrm{G}}$ enable the development of an assessment process taking into account the average intensity of the material, the shape of the micro-edges detected on the fibres, and the shape and size of the holes visible between the fibres. Based on the analysis, the user is presented with a resulting image with a marked degree of cleanliness of the material.

The proposed vision algorithm enables precise examination of the following: the degree of contamination of the material, both cotton and polyester, the control of textile structure, such as the size of openings in the material and their shape, and the control of the defects associated with the rupture or entanglement of fibres of the textile as shown in the weaving pattern (Fig. 11).

Analysis of the size of the openings in the textile material in accordance with the algorithm can detect a very clear distinction between clean and dirty samples. That index is 
also used as an aid to assess the cleanliness of the material. Analysis of the image after binarization allows us to conduct a comparative evaluation of the materials' surface and carry out an indirect assessment of the degree of soiling of the materials.

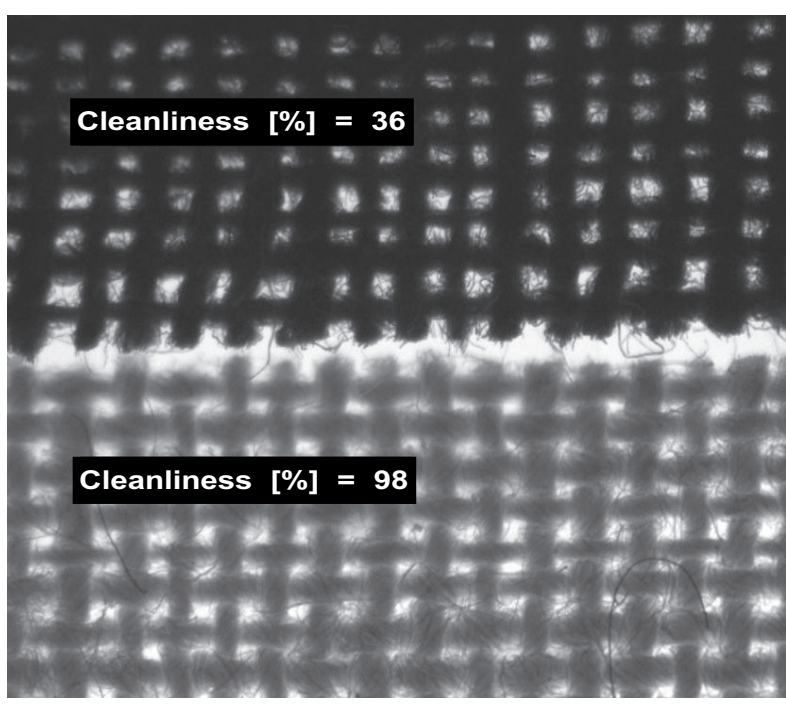

Fig. 11. Cleanliness examination result for both materials

Comparing the image of the material made of polyester and cotton makes it also possible to assess the packing of fibres in a selected unit of the surface area.

\section{ANALYSIS OF FABRIC CLEANLINESS WITH A NANO-SCANNER}

The study used a microscope designed for research in nanoscale. The device is a combination of AFM and STM technology, enabling the study of both conductive non-conductive materials. In studying polyester and cotton, the AFM function of the microscope was used to reproduce the topography of the individual fibres in the material. The aim of the study in nano-scale was to verify the possibility of detecting contamination on the fibres and the possibility of imaging such cleanliness defects onto the image of fibre surface topography. Additionally, the possibility of imaging fibres and defects on three-dimensional images in the nanometre scale was tested. In Figure 12 is a microscope fitted with a measuring head and a scanner table that moves the tested material.

The measuring head is fitted with a probe, whose purpose is to reconstruct the topography of the tested surface. As it approaches the material, it is subjected to the forces of intermolecular interactions that change the frequency of its operation. Those changes are recorded by the probe drive system, which reads the current height of the probe for each measurement point. By changing the position of the table in axis $\mathrm{X}$ and $\mathrm{Y}$, the microscope reads the height of all points within the adopted range of testing.

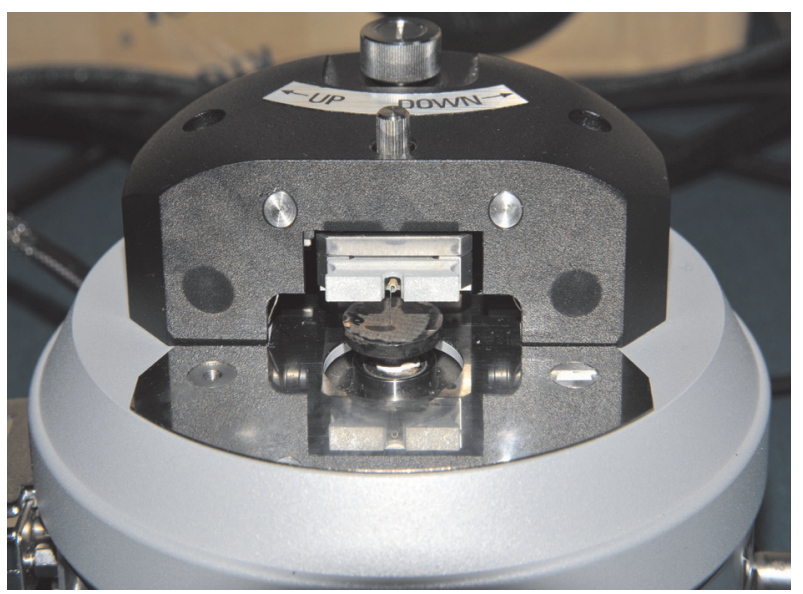

Fig. 12. AFM microscope for nano-scale examination

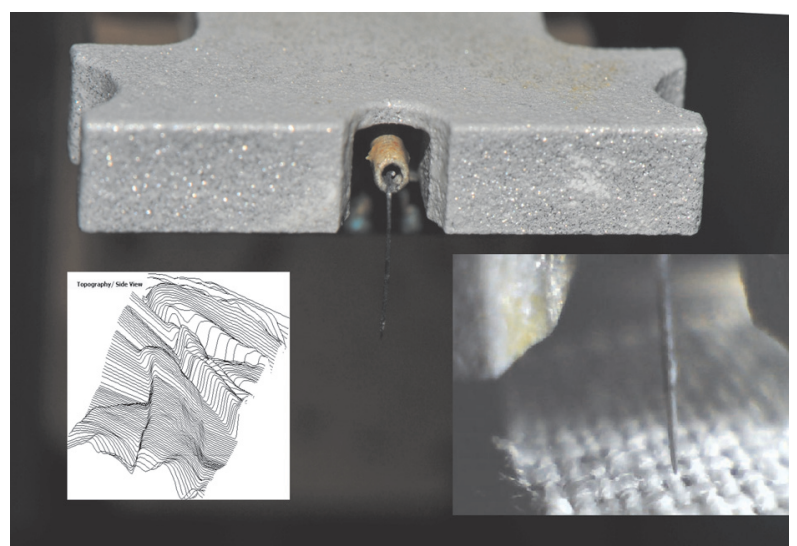

Fig. 13. View of the head with a scanning probe

To register a change in distance between the probe and a sample surface (Z), the same methods are used as in atomic force microscopy. The most widely used is the "shear-force" method and registration of probe position by a deflectometre.

The "shear-force" method is based on the detection of changes in the oscillation frequency of the probe caused by the tangential component of the forces of interaction between the probe and the surface. To determine changes in oscillation frequency, tuning fork resonators are used, which detect oscillation by the direct piezoelectric effect of a quartz crystal.

As part of the study, a surface of clean and dirty cotton was scanned with a nano-scanner. Scanning was performed over an area of $86 \times 86 \mu \mathrm{m}$ at 8000 and $16000 \mathrm{~nm} / \mathrm{s}$ (Fig. 13). Following the test, it was observed that a further increase of the scanning speed results in significant deterioration in the quality of the resulting image.

Figure 14 shows a probe scanning of the tested material. The probe is moved over a length of $85 \mu \mathrm{m}$ in axis $\mathrm{X}$, collecting all the points of the profile within the range of the nanometre with the adopted scanning progress. After construction of the first profile has been completed, it is 
moved in axis $\mathrm{Y}$ by the pre-set step and re-scans along axis X. Such profiles are then used to construct a three-dimensional image of the surface topography in nanometre scale, as can be seen in Figure 12.

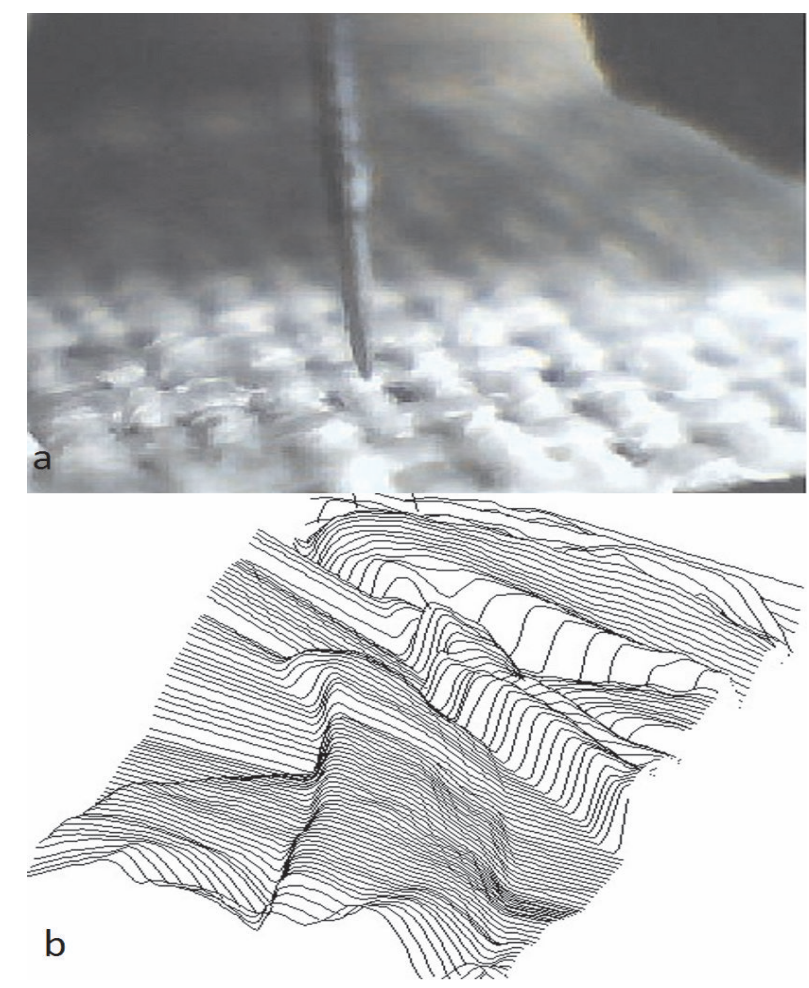

Fig. 14. Scanning probe above the material and topography of the surface of clean cotton fibres

With respect to such an image, imaging is also conducted with the application of colours depending on the height of the material at the different points in the image. Figure 15 shows a section of cotton fibre weave pattern in textile material. The surfaces of individual fibres and the arrangement of fibres woven to form a cotton thread are clearly visible.

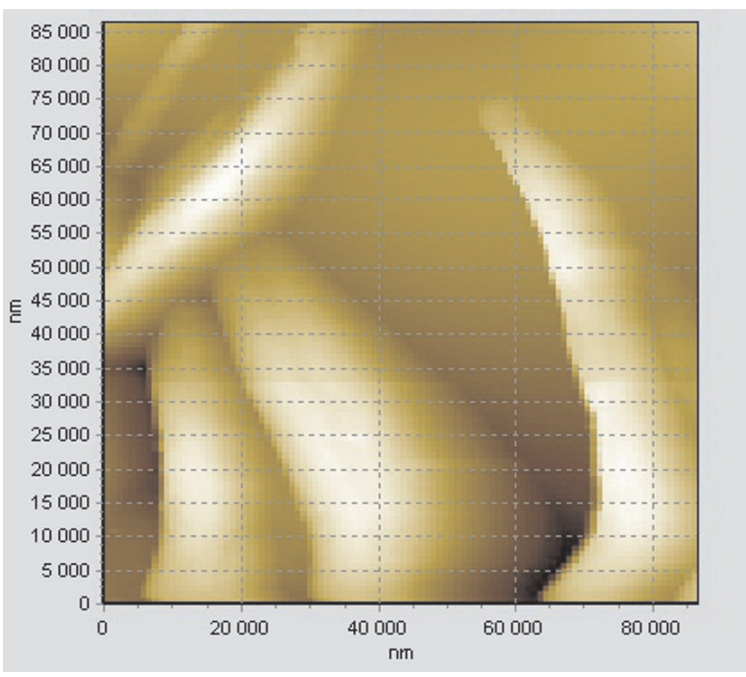

Fig. 15. A three-dimensional image with added colours depending on the height of the material
The surfaces of fibres of clean cotton material are smooth and no inclusions can be seen between the fibres. That image can be treated as a reference image necessary for the comparative analysis with an image of material soiled with oil and pigments. The figure also shows descriptions of the dimensions of the scanning areas.

In the next stage of this study, the surface of the material soiled with oil and pigments was scanned, with the dimensional parameters of the scanning field and the scanning speed remaining identical as previously (Fig. 16). Such action is intended to obtain an image of the dirty material for a comparative analysis enabling the detection of the differences between the dirty and the clean material.

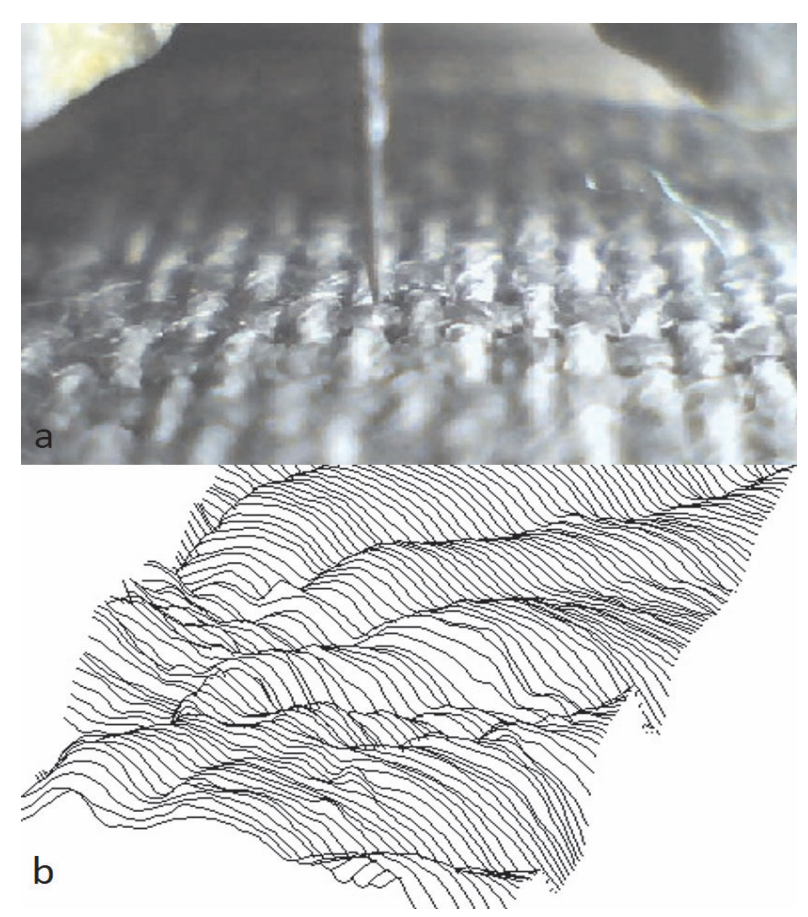

Fig. 16. Scanning probe and topography of the surface of dirty cotton fibres

A three-dimensional representation of the surface of dirty cotton fibres is shown in Figure 17.

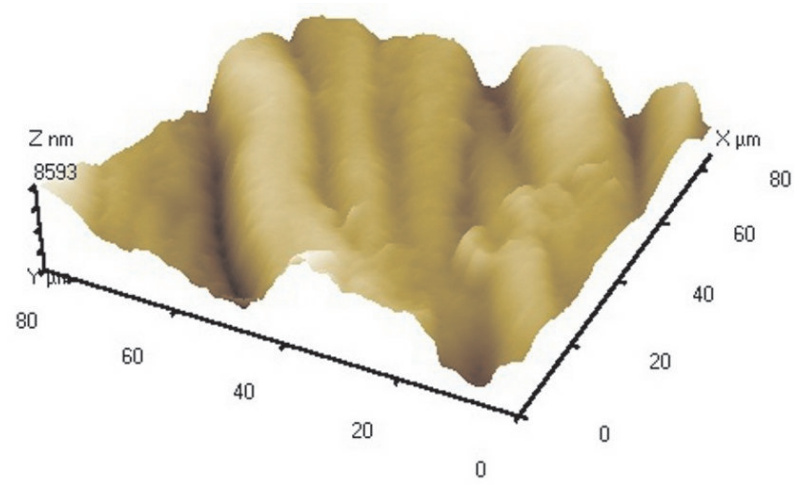

Fig. 17. A three-dimensional image with added colours depending on the height of the material 
The image of the surface of soiled cotton fibres reveals the presence of oil and pigment particles stuck to the surface of the fibre. This can be seen as a rough surface on the individual cotton fibres shown in Figure $18 \mathrm{~b}$ is detail 1. There is also a larger disruption of the surface in the form of excess material, visible in Figure $18 \mathrm{~b}$ as detail 2. Figure 18a shows the surface of the material adopted in the study as clean reference material.
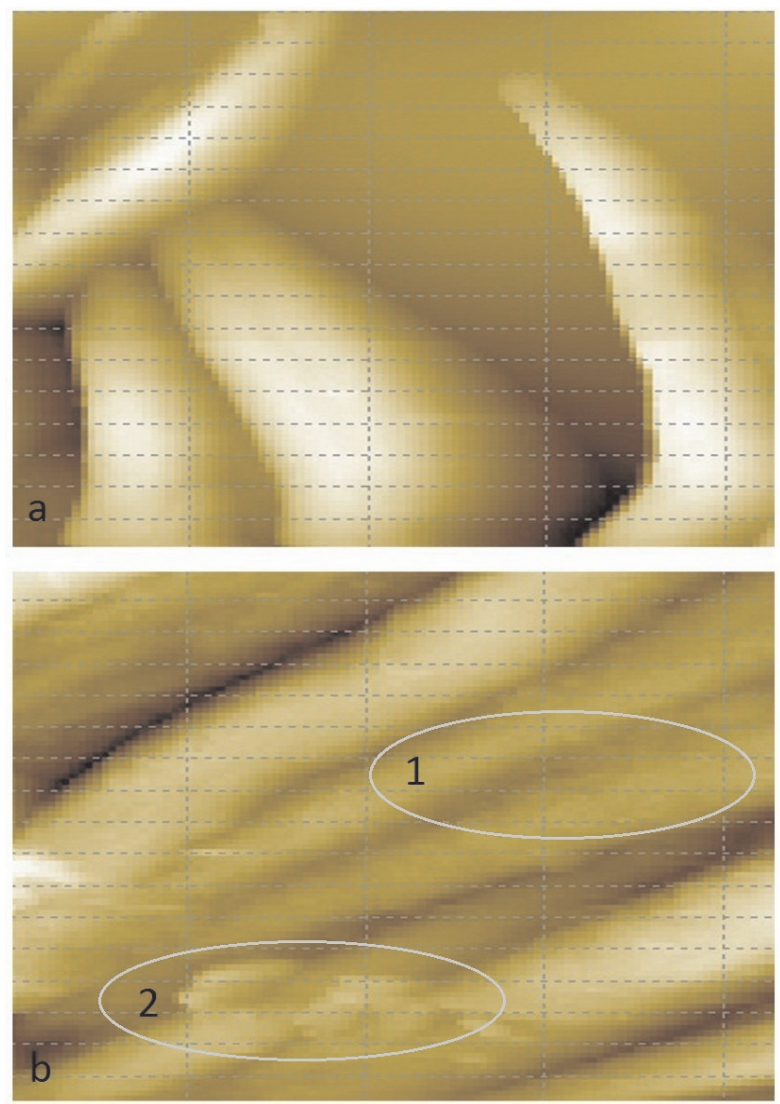

Fig. 18. 3D images of the surface of dirty cotton material

\section{CONCLUSIONS}

This paper presents two methods for measuring the cleanliness of textile materials. The first is based on cleanliness assessment based on an analysis of an image obtained by a vision system. That method enables rapid and accurate assessment of cleanliness based on predetermined indices that allow for the assessment of multiple parameters associated with textile material cleanliness. That method is designed for industrial applications as confirmed during tests.

The second method is based on studies of material structure in the nanometre range, which allows fibres. However, both the duration of testing and the conditions required to carry out such testing place that method in the group of laboratory methods.

\section{Acknowledgements}

The research work is supported by the Ministry of Education, Science, Youth and Sports of Ukraine as a part of Scientific Project "Development of New Formulations of Compositions to Improve Technological Processing Efficiency of Textile Materials", Grant No. 0111 U002297.

Vision and nano-technological tests were conducted in the Department of Process Control at the AGH University of Science and Technology, Krakow, Poland, under research project no. N N502 337336 funded by the Scientific Research Committee.

\section{References}

Fedorova A.F. 2005, Technology of dry-cleaning, Moscow, 560 p.

Karvan S.A., Bubencshikova G.T., Paraska O.A. 2003, Soil removal of various nature from textile materials in the processes of dry-cleaning, Problems of Light and Textile Industries of Ukraine, No. 1(7), pp. 37-39.

Paraska O.A., Karvan S.A., Kulakov O.I. 2006, Analysis of measuring methods of washing ability of surfactants, Visnik KNUTD, No. 2, pp. 83-87.

Paraska O.A., Karvan S.A. 2010, Research of properties of textile materials after treatment in aqueous and nonaqueous mediums, Problems of Light and Textile Industries of Ukraine, No. 1(16), pp. 35-38.

Paraska O.A. 2010, Modern methods of investigation of surface of textile materials, Light Industry, No. 3, pp. 48-49.

Volkov V.A. 1985, Surface-active substances in detergents and dry-cleaning, Moscow, $200 \mathrm{p}$.

Sioma A. 2011, Modelowanie i symulacja realizacji procesu technologicznego [Modelling and simulation of processes] Mechanik miesięcznik naukowo-techniczny, ISSN 0025-6552, No. 12, p. 990.

Sioma A. 2010, Zastosowanie systemów wizyjnych 3D w kontroli jakości wykonania elementów pneumatyki i hydrauliki [Using 3D vision systems in the quality inspection of pneumatic and hydraulic components] Pneumatyka, ISSN 1426-6644, No. 1, pp. 27-30.

Kowal J., Sioma A. 2010, Metoda budowy obrazu 3D produktu z wykorzystaniem systemu wizyjnego [Construction of a 3D image of a product using a vision system] Acta Mechanica et Automatica, ISSN 18984088, Vol. 4, No. 1, pp. 48-51.

Kowal J., Sioma A. 2009, Active vision system for $3 D$ product inspection. Learn how to construct three-dimensional vision applications by reviewing the measurements procedures, Control Engineering USA, vol. 56 , pp. $46-48$. 